\title{
DESMAME PRECOCE E SUAS CAUSAS: EXPERIÊNCIA NA ATENÇÃO BÁSICA DE CAMPINA GRANDE-PB ${ }^{1}$
}

\author{
Janaina Pessoa ARAÚJO ${ }^{2}$ \\ Jank Landy Simôa ALMEIDA ${ }^{3}$ \\ Cláudia Maria Ramos Medeiros SOUTO ${ }^{4}$ \\ Ana Emília Araújo de OLIVEIRA ${ }^{5}$ \\ Maria Aparecida Rocha Pontes SUDÉRIO ${ }^{6}$
}

\begin{abstract}
${ }^{1}$ Texto extraído da monografia intitulada "Benefícios do Aleitamento Materno e Causas do Desmame Precoce: Experiência em Unidade de Saúde da Família em Campina Grande-PB” da UNESC Faculdades.

${ }^{2}$ Enfermeira. Especialista em Saúde da Família / Faculdades Integrada de Patos. janyaraujo.cg@ gmail.com.

${ }^{3}$ Enfermeiro. Mestre. Professor da UFCG e Coordenador de Pesquisa e Extensão da UACS/UFCG - Campina Grande. Participante do Núcleo de Pesquisa em Saúde e Enfermagem (NUPESEN). jankalmeida@ig.com.br.

${ }^{4}$ Enfermeira. Doutora em Enfermagem. Docente do Programa de Pós-Graduação em Enfermagem/UFPB; Docente do Departamento de Enfermagem de Saúde Pública e Psiquiatria/CCS/UFPB. Líder do Grupo de Estudos e Pesquisas Saúde, Mulher e Gênero - GEPSAM. claudiaramos.enf@gmail.com.

${ }^{5}$ Enfermeira. Especialista em Enfermagem em Obstetrícia; Pós Graduando em Gestão. anaemiliaoliveira@ hotmail.com.

${ }^{6}$ Enfermeira. Especialista em Saúde da Família; Especialista em Enfermagem Dermatológica: Cuidados em feridas e estômias; Membro Executor da CCIH-HETDLGF CG. cidarpontes@ hotmail.com.
\end{abstract}

Autora correspondente: Janaina Pessoa Araújo ${ }^{2}$

Recebido em: 17/09/2013 - Aprovado em: 14/12/2013 - Disponibilizado em: 15/01/2014

RESUMO: O Desmame precoce continua presente na sociedade e caracteriza-se pela introdução de outros alimentos ou líquidos durante o período de amamentação exclusiva. Este estudo objetivou descrever os fatores que levam ao desmame precoce. Tratou-se de uma pesquisa de campo de natureza exploratória, descritiva e quantitativa. A população estudada foi composta por 74 puérperas cujos filhos eram menores de 01 ano, por sua vez a amostra foi composta por 68 mulheres. Constatou-se que 45,4\% das mães estavam na faixa etária entre 20 a 24 anos, $77,3 \%$ eram solteiras; 36,4\% tinham baixa escolaridade e $63,6 \%$ não exerciam nenhuma atividade remunerada. A maioria das mães (50\%) amamentou por menos de um mês. Dentre os motivos de desmame precoce $18,2 \%$ das mães não tinham leite suficiente; $18,2 \%$ dos bebês recusaram o peito; $9,1 \%$ das mães não tinham mamilos favoráveis para amamentação e $9,1 \%$ apresentaram problemas nas mamas, vale ressaltar que $45,4 \%$ destas relataram outros motivos. É fundamental o investimento na promoção do aleitamento materno exclusivo, especialmente em comunidades menos privilegiadas sócio-economicamente ao longo do ciclo gravídico-puerperal potencializando a relação salutar no binômio mãe-filho.

Palavras-chave: Aleitamento materno. Desmame precoce. Enfermagem. Atenção Básica. Causas.

ABSTRACT: Precocious Desmame continues present in the society and characterizes for the introduction of other foods or liquids during the period of exclusive breast-feeding. This study it objectified to describe the factors that lead to wean it precocious. One was about a research of field of exploratória, descriptive and quantitative nature. The studied population was composed for 74 puérperas whose 01 children were lesser of year, in turn the sample was composed for 68 women. $77.3 \%$ were evidenced that $45.4 \%$ of the mothers were in the etária band enter the 2024 years, were single; $36.4 \%$ had low escolaridade and $63.6 \%$ did not exert no remunerated activity. The majority of the mothers (50\%) 
suckled for less of one month. Amongst the reasons of it weans precocious $18.2 \%$ of the mothers did not have enough milk; $18.2 \%$ of the babies had refused the chest; $9.1 \%$ of the mothers did not have favorable mamilos for breast-feeding and $9.1 \%$ had presented problems in the breasts, valley to stand out that $45.4 \%$ of these had told other reasons. The investment in the promotion of the exclusive maternal aleitamento is basic, in communities especially less privileged partner-economic throughout the gravídico-puerperal cycle potencializando the relation to salutar in the binomial mother-son.

Key Word: Maternal Aleitamento. It weans precocious. Nursing. Basic attention. Causes.

\section{INTRODUÇÃO}

O leite materno, como já amplamente discutido na literatura, fornece ao lactante um alimento ideal durante os seis primeiros meses de vida, devido à disponibilidade de nutrientes e substâncias imunológicas para o crescimento e desenvolvimento da criança e deve ser encorajado até os dois anos de forma complementar (VIEIRA, 2009).

O leite materno apresenta numerosos fatores que protege o bebê de infecções como a diarréia, otite média e doenças respiratórias agudas, bem como promove uma excelente nutrição, favorecendo ao crescimento e desenvolvimento das crianças e consequentemente a redução da morbidade e mortalidade infantil (BRASIL, 2012).

Destarte, a amamentação protege a mulher contra o câncer de mama e de ovário, estende o espaçamento entre os partos, ajuda o corpo de a mulher voltar ao normal muito mais rápido e fornecer a expressiva vantagem econômica (MARTINS; SANTANA, 2013).

$\mathrm{O}$ desmame precoce sofre influência de variáveis que afetam a extensão do aleitamento materno exclusivo, podendo ser divididas em cinco categorias: fatores demográficos; socioeconômico; assistência pré-natal e à assistência pós-natal (ARAÚJO et al., 2008).

O desmame precoce é uma das principais causas de doenças em crianças, levando à desnutrição e consequentemente a mortalidade infantil no primeiro ano de vida, sendo o fator principal a doença diarréica, com a introdução precoce de alimentos (PASSANHA; CERVATOMANCUSO; SILVA, 2010).

Assim, percebendo a taxa de mortalidade neonatal devido à preponderância do desmame precoce, identificou-se a relevância de um estudo que abordasse os benefícios do aleitamento materno para a mãe e para o bebê, e os efeitos deletérios do desmame precoce. A presente pesquisa objetivou-se de forma geral em demonstrar os benefícios do aleitamento materno e os fatores que levam ao desmame precoce, especificando o perfil epidemiológico das mães pesquisadas, os prejuízos causados pelo desmame precoce e quantificar o número de mães que interromperam o aleitamento materno e seus motivos. 


\section{MÉTODOS}

Estudo de caráter exploratório, descritivo e bibliográfica com abordagem quantitativa, realizado na Unidade Básica de Saúde da Família José Pinheiro I no município de Campina Grande-PB.

A amostra foi selecionada por conveniência mediante realização de visitas domiciliares depois da identificação das puérperas com a equipe da Unidade de Saúde no período em outubro de 2009.

A pesquisa foi feita com 68 puérperas que ofereceram amamentação exclusiva ao filho por tempo inferior a 6 meses dentro de um universo total de 74 mulheres com até 1 ano de pós-parto cadastradas na área de abrangência da Unidade Básica de Saúde e que concordaram em participar do estudo mediante assinatura do Termo de Consentimento Livre e Esclarecido. A realização da pesquisa foi efetivada após aprovação desta pelo Comitê de Ética em Pesquisa, sob o número 3274.0.000.133-09.

Para a coleta de dados empíricos utilizou-se um formulário estruturado. Esses foram organizados e apresentados por representação tabular com o auxílio do programa Microsoft Excel@ versão 2007, e analisados à luz da estatística descritiva e da literatura.

\section{RESULTADOS E DISCUSSÃO}

A tabela 01 descreve o perfil epidemiológico das puérperas que introduziram de forma precoce na alimentação de seus filhos outro alimento que não o leite materno.

Tabela 01 - Perfil Epidemiológico das Puérperas Entrevistadas

\begin{tabular}{|c|c|c|}
\hline Idade & $\mathrm{N}=68$ & $100 \%$ \\
\hline 15 a 19 anos & 06 & 8,8 \\
\hline 20 a 24 anos & 23 & 33,8 \\
\hline 25 a 29 anos & 15 & 22,1 \\
\hline 30 a 34 anos & 14 & 20,6 \\
\hline 35 a 39 anos & 10 & 14,7 \\
\hline Religião & $\mathrm{N}=68$ & $100 \%$ \\
\hline Católica & 44 & 64,7 \\
\hline Evangélica & 11 & 16,2 \\
\hline Outras & 13 & 19,1 \\
\hline Escolaridade & $\mathrm{N}=68$ & $100 \%$ \\
\hline Analfabeta & 04 & 5,9 \\
\hline Fundamental completo & 04 & 5,9 \\
\hline Fundamental incompleto & 39 & 57,3 \\
\hline Médio completo & 10 & 14,7 \\
\hline Médio incompleto & 08 & 11,8 \\
\hline Superior completo & 02 & 2,9 \\
\hline Superior incompleto & 01 & 1,5 \\
\hline Estado civil & $\mathrm{N}=68$ & $100 \%$ \\
\hline Solteira & 42 & 61,8 \\
\hline Casada & 21 & 30,9 \\
\hline Relacionamento estável & 02 & 2,9 \\
\hline Divorciada & 03 & 4,4 \\
\hline Profissão & $\mathrm{N}=68$ & $100 \%$ \\
\hline Do lar & 47 & 69,1 \\
\hline Ocupação remunerada & 21 & 30,9 \\
\hline TOTAL & $\mathrm{N}=68$ & $100 \%$ \\
\hline
\end{tabular}

Fonte: UBSF José Pinheiro - Campina Grande (PB); Pesquisa de Campo, 2009.

A maioria das mães entrevistadas $33,8 \%$ encontra-se no intervalo de 20 a 24 anos; $22,1 \%$ entre 25 e 29 anos; $20,6 \%$ entre 30 e 34 anos; $14,7 \%$ entre 35 e 39 anos e $8,8 \%$ entre 15 e 19 anos. 
Em relação à faixa etária a pesquisa de Pereira, Fernandes e Sabates (2012), a idade materna permaneceu como fator de risco para o desmame, visto que, a prevalência da amamentação por seis meses mínimos foi menor em mães adolescentes.

De acordo com a religião; $64,7 \%$ da amostra era constituída por católicas; $16,2 \%$ por evangélicas e $19,1 \%$ de outra religião. A crença de uma pessoa, sua visão de mundo ou sua espiritualidade podem influenciar sua saúde. Principalmente no tocante à amamentação, os mitos ou tabus a ela relacionados podem trazer transtornos ou interferir na prática do aleitamento materno (DEL CIAMPO et al., 2008).

Relacionando o grau de escolaridade, a maior parte da amostra $(57,3 \%)$ possuía apenas o ensino fundamental incompleto; seguido de $14,7 \%$ de mulheres que possuíam o ensino médio completo.

No que se refere ao grau de instrução materna, estudos têm demonstrado que esse fator afeta a motivação para amamentar. Em muitos países desenvolvidos, mães com maior grau de instrução tendem a amamentar por mais tempo, isto se dá pelo fato da possibilidade de um maior acesso a informações sobre as vantagens do aleitamento materno. Já em países em desenvolvimento, as mães de classes menos favorecidas e instruídas, freqüentemente, não casadas, começam o pré-natal mais tarde e, conseqüentemente, se preocupam em decidir sobre a forma de alimentação do bebê também mais tarde (ARAÚJO et al., 2008).

Pereira, Fernandes e Sabates (2012) enfoca que mulheres com maior escolaridade estão em fase de valorização do AME, porém, esta tendência ainda não atingiu mulheres de estratos socioeconômicos menos favoráveis, o número das taxas de interrupção precoce do aleitamento é expressivo entre mulheres menos instruídas.

Quanto ao estado civil das entrevistadas, verificou-se um relevante número de solteiras 61,8\%; já 30,9\% das pesquisadas eram casadas; 2,9\% com relacionamento estável e 4,4\% eram divorciadas.

$\mathrm{O}$ estado conjugal apresentou fortes influências sobre o desmame precoce em mães adolescentes, as análises mostraram que nestas, a existência de vida conjugal favoreceu o aleitamento materno prolongado, visto que o quantitativo de desmame em mães adolescentes sem vida conjugal foi bem significativo (FALEIROS; TREZZA; CARANDINA, 2006).

Observando o número de mulheres empregadas identificou-se que uma porcentagem correspondente a 30,9\% da amostra exerciam atividades remuneradas fora ou dentro do domicílio, em contra partida a maior parte do total de pesquisadas, ou seja, 69,1\% não exerciam nenhuma ocupação remunerada. 
Soleva-se que o trabalho materno pode ser uma das principais causas do desmame precoce pelo fato de $40 \%$ das mães incluídas no estudo sentirem-se inibidas e ansiosas com a volta ao trabalho dificultando o aleitamento; isto pelo fato de que no Brasil são poucos os locais de trabalho que permitem o acompanhamento da criança junto à mãe (PARIZOTTO; ZORZI, 2008).

O trabalho fora do lar só é agravante para o desmame se não houver condições favoráveis a manutenção do aleitamento, assim como o número de horas trabalhadas associadas à dupla jornada de trabalho, ou seja, os trabalhos domésticos (FALEIROS, TREZZA e CARANDINA, 2006).

Figura 01 - Quantitativo de mães que introduziram outros alimentos e/ou líquidos durante o período de aleitamento materno exclusivo.

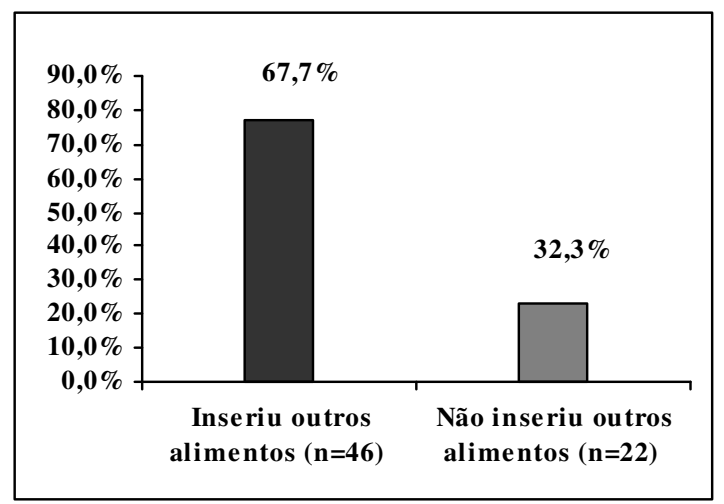

Fonte: UBSF José Pinheiro - Campina Grande (PB); Pesquisa de Campo, 2009.

De acordo com os dados supracitados, verifica-se o número de mães que introduziram outro alimento e/ou líquido no período do AME com percentual significante de $67,7 \%$ em contrapartida $22,7 \%$ não introduziram nenhum alimento e/ou líquido.
O Ministério da Saúde (2009) ressalta que a inserção de água, chá e principalmente outros tipos de leites sejam evitados, pois existem evidências que o consumo destes esteja associado ao desmame precoce e ao aumento da morbimortalidade infantil, sendo desnecessário nos primeiros seis meses de vida.

Figura 02 - Duração média do aleitamento materno exclusivo.

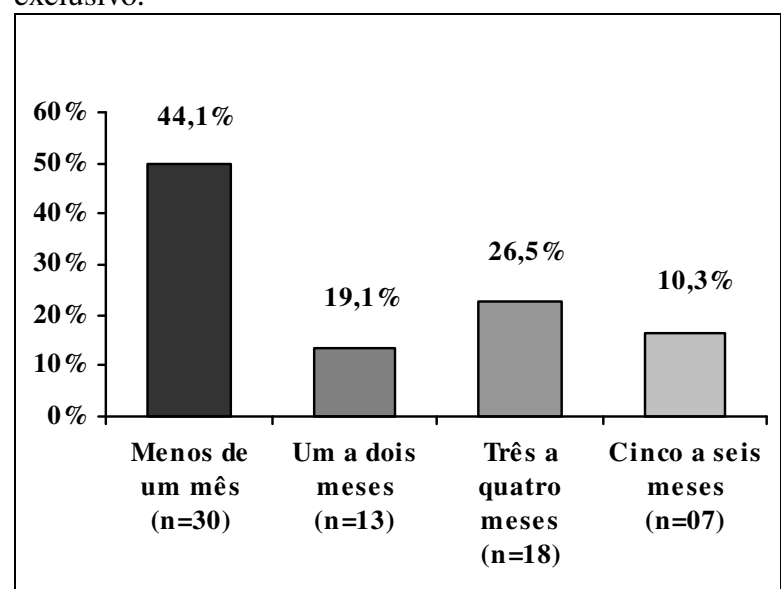

Fonte: UBSF José Pinheiro - Campina Grande (PB); Pesquisa de Campo, 2009.

Conforme a figura 02 mostra, a maioria das mulheres $(44,1 \%)$ amamentou exclusivamente ao peito por menos de um mês, este valor é seguido de $26,5 \%$ do total referendando que a amamentação durou de três e quatro meses; por sua vez 19,1\% representam o total de mulheres que exerceram AME entre um e dois meses e $10,3 \%$ entre cinco a seis meses.

A organização Mundial da Saúde (OMS) e o Ministério da Saúde (MS) recomendam aleitamento materno exclusivo 
por seis meses e complementado até os dois anos ou mais (BRASIL, 2009).

Tabela 02 - Descrição dos motivos que levaram ao desmame precoce das crianças

\begin{tabular}{ccc}
\hline Variáveis & N & \% \\
\hline Não tinha leite suficiente & 18 & 26,5 \\
O bebê recusou o peito & 16 & 23,5 \\
Não tinha bico favorável & 05 & 7,3 \\
Apresentou problemas na mama & 04 & 5,9 \\
Outros motivos & 25 & 36,8 \\
\hline Total & $\mathbf{6 8}$ & $\mathbf{1 0 0} \%$
\end{tabular}

Fonte: UBSF José Pinheiro - Campina Grande (PB); Pesquisa de Campo, 2009.

Dentre os motivos para a interrupção do aleitamento exclusivo de forma precoce (figura 03);26,5\% da amostra não tinham leite suficiente; $23,5 \%$ das mães relataram que o bebê recusou o peito; 7,3\% não tinham bico favorável e $5,9 \%$ do total apresentou problemas nas mamas, sendo $36,8 \%$ das mulheres relataram outros motivos.

O Ministério da Saúde (2009) ressalva que alguns problemas enfrentados pelas nutrizes durante o aleitamento materno que se não forem precocemente identificados $\mathrm{e}$ tratados podem levar ao desmame precoce.

A maioria das mulheres tem condições biológicas de produzir leite, no entanto, usa o argumento que o leite é fraco ou que não tem leite suficiente, estes são citados frequentemente para a introdução de complementos (MARQUES; COTTA; PRIORE, 2011).

Dentre os principais motivos que levam ao desmame precoce apresentados em outros estudos, a maioria das mães (30\%) entrevistadas relatou que o leite secou, talvez esteja relacionado pelo fato da insegurança materna em relação à produção do leite, outros estudos destaca como uma das causas do aleitamento materno exclusivo é a rejeição da criança pelo peito (CYSNE e CARDOSO, 2007).

Os problemas mamários estão dentre os principais motivos que levam ao desmame precoce, mamilos planos ou invertidos podem dificultar o inicio da amamentação, mas não a impedem. Uma boa técnica de amamentação é imprescindível para o seu sucesso, prevenindo traumas mamilares. Muitas mulheres apresentam problemas com os mamilos, sendo a dor e fissuras como a principal dificuldade para amamentar nas primeiras semanas após o nascimento (BRASIL, 2009).

Tabela 03 - Associação de patologias freqüentes na infância relacionadas à dieta mista pós desmame precoce

\begin{tabular}{ccc}
\hline Apresentaram pato & $\mathbf{N = 6 8}$ & $\mathbf{\%}$ \\
\hline Sim & 28 & 41,2 \\
Não & 40 & 58,8 \\
\hline TOTAL & $\mathbf{6 8}$ & $\mathbf{1 0 0}$ \\
\hline
\end{tabular}

Fonte: UBSF José Pinheiro I, 2009 (Pesquisa de campo).

Em relação ao surgimento de alguma morbidade infantil associada ao desmame precoce (figura 05), constatou-se que 58,8\% dos filhos não apresentaram nenhuma patologia e $41,2 \%$ destes tiveram conseqüências mórbidas.

O aleitamento exclusivo é de suma importância, especialmente quando se trata da 
população menos favorecida, já que a amamentação é um fator de proteção contra doenças diarréicas, infecciosas e do trato respiratório. Estas morbidades estão presentes em maior número no $2^{\circ}$ trimestre, pelo fato deste ser o período menor de crianças em AME (BARBOSA et al, 2009). Gomes e Nakano (2007) revelam em sua pesquisa, dados de crianças que recebiam outros alimentos no primeiro mês, ou seja, crianças que não estavam sendo beneficiadas com o aleitamento. Vale ressaltar que a desnutrição, o atraso do crescimento e a morbimortalidade infantil, estão associadas à introdução de alimentos complementares, isto pelo fato do consumo de alimentos nutricionalmente inadequado e/ou contaminados.

O leite humano é bacteriologicamente seguro e do ponto de vista imunológico apresenta um fator de proteção e defesa contra infecções, em especial as gastrintestinais. Sendo o alimento mais eficiente para atender os aspectos nutricionais para suprir uma criança até os seis meses de idade, como também o aspecto psicológico e o desenvolvimento necessário no seu primeiro ano de vida. Crianças que são amamentadas apresentam um melhor desenvolvimento psicomotor, visual, melhor capacidade de aprendizado e menos transtornos da linguagem que as que são alimentadas com formulas lácteas (SCHMITZ, 2005).

\section{CONCLUSÃO}

Considerando que o leite materno é o alimento ideal e dispõe de nutrientes e substâncias imunológicas durante os seis primeiros meses de vida do bebê, é dispensável qualquer outro tipo de alimento ou liquido na dieta do lactente. O mesmo oferece inúmeras vantagens, tanto para mãe quanto para o bebê; apesar desta gama de benefícios, observa-se ainda no Brasil um grande índice de mortalidade infantil decorrente da desnutrição, ocasionado pela interrupção precoce do aleitamento materno.

$\mathrm{Na}$ presente pesquisa foi enfatizado o fato de que o desmame precoce continua sendo um evento preocupante, provocando efeitos deletérios para crianças e elevando a incidência da morbimortalidade infantil.

Quanto aos prejuízos causados pelo desmame precoce é lícito alegar que se destaca a baixa imunidade da criança o que vai beneficiar as morbidades como infecções comuns, alergias, diarréias, doenças respiratórias, desnutrição entre outras, e predispõe morbidade em longo prazo, tais como hipertensão, colesterol alto e diabetes. Este também influencia a má oclusão dentária e as práticas alimentares, podendo aprazar o crescimento e desenvolvimento infantil.

Para a mãe poderá ocorrer à quebra da proteção contra o câncer de mama e ovário, a redução do peso no primeiro mês após o parto e com o desmame haverá um acréscimo 
significante nas despesas com os substitutos do leite materno.

São inúmeras as vantagens do aleitamento materno, tanto para a mãe quanto para o bebê. O leite materno representa um ato de amor, vínculo de segurança e uma fonte de nutrientes adaptado para o metabolismo do lactente, dando-lhe proteção imunológica contra doenças, além de promover efeitos benéficos para o quociente de inteligência, desenvolvimento cognitivo e psicomotor, como também satisfaz psicológicologicamente a dupla mãe/bebê.

Permanece a excelente qualidade do leite materno como único e ideal alimento para o bebê até os seis meses de vida, e sendo prolongado até os dois anos de idade como complemento, portanto não é necessária a introdução na dieta do bebê outros tipos de alimentos ou água e chás ou qualquer outro liquido apenas gotas, xaropes e vitaminas se for preciso.

Apesar de todas as evidencias científicas provando os benefícios do aleitamento materno sobre outras formas alimentares, a prática da amamentação é influenciada pelo meio onde está inserida a nutriz.
No entanto é necessária a intensificação das ações de incentivo ao aleitamento materno, no intuito de reduzir bruscamente o índice de desmame precoce. Para que isto aconteça se faz necessário o investimento em ações de capacitações para os profissionais; que haja sensibilização destes profissionais no atendimento a gestante no período pré-natal e no puerpério (sendo esta a fase de maior índice de problemas relacionados com a amamentação).

O Programa de Saúde da Família tem relevante importância na prática do aleitamento, pois inúmeras são as gestantes acompanhadas por esta estratégia em nível de saúde pública. As orientações acontecem desde o planejamento familiar, continuando no pré-natal e se estendendo do puerpério até a fase de aleitamento materno exclusivo na puericultura. $\mathrm{O}$ enfermeiro presta orientações visando o bem estar da mãe e do bebê, incentivando o aleitamento materno não só a ela, como também ao companheiro, a família e a comunidade, a fim de sensibilizar a população de que este é o método ideal de alimentar um neonato. 


\section{REFERÊNCIAS}

ANTUNES, L. S.; ANTUNES, L. A. A.; CORVINO, M. P. F.; MAIA, L. C.

Amamentação natural como fonte de prevenção em saúde. Ciência \& Saúde Coletiva, 13(1):103-109, 2008.

ARAÚJO, O. D. A. et al. Aleitamento materno: fatores que levam ao desmame precoce. Rev Bras Enferm, Brasília, 2008. jul-ago; 61(4): 488-92.

BRASIL. Ministério da Saúde. Saúde da criança: crescimento e desenvolvimento / Ministério da Saúde. Secretaria de Atenção à Saúde. Departamento de Atenção Básica. Brasília : Ministério da Saúde, 2012.

BRASIL. Ministério da Saúde. Estatuto da criança e do adolescente. Brasília, 2006. Editora do Ministério da saúde.

BRASIL. Ministério da Saúde. Secretária de atenção a saúde. Departamento de atenção básica. Saúde da criança: nutrição infantil: aleitamento materno e alimentação complementar. Brasília, 2009. Editora do Ministério da Saúde.

CARRASCOZA, K. C.; JÚNIOR, A. L.; MORAES, A. B. A. Fatores Que influenciam o desmame precoce e a extensão do aleitamento materno. Estud. psicol. (Campinas), Campinas, v. 22, n. 4, dezembro 2005.

CYSNE, M. M. O.; CARDOSO, P. C. Avaliação da prática da amamentação e do desmame precoce no município de Coronel Fabriciano-MG. Nutrir Gerais - Rev. Digital de Nutrição - Ipatinga: Unileste-MG, v.1, n. 1 - ago/dez. 2007.

BARBOSA, M. B. et al. Fatores de risco associados ao desmame precoce e ao período de desmame dos lactentes matriculados em creches. Rev. Paul. Pediatr. 2009 Set; 27 (3): 272-281.
DEL CIAMPO, L. A. et al,. Aleitamento materno e alimentares tabus. Rev. paul. Pediatr. 2008 Dez; 26 (4): 345-349

FALEIROS, F. T. V.; TREZZA, E. M. C; CARANDINA, L. Aleitamento materno: Fatores de influência na sua decisão e duração. Rev. Nutr. 2006 Out; 19 (5): 623630 .

GOMES, P.T.T.; NAKANO, A. M. S. Introdução complementar em crianças menores de seis meses atendidas em dia nacional de campanha de vacinação. Revista Salus - Guarapuava - PR. Jan./Jun. 2007; (1)1.

LEITE, A. C. N. M. T.; BEZERRA, T. P. Desmame precoce: associação entre variáveis. [Monografia]. Faculdade de Campina Grande-FAC-CG - Campina Grande: UNESC, 2008.

MARQUES, E. S.; COTTA, R. M. M.; PRIORE, S. E. P. Mitos e crenças sobre o aleitamento materno. Ciência \& Saúde Coletiva, 16 (5): 2461-2468, 2011.

MARTINS, M. Z. O.; SANTANA, L. S. Benefícios da amamentação para saúde materna Interfaces Científicas - Saúde e Ambiente. Aracaju. V.1. N.3. p. 87-97. jun. 2013.

OLIVEIRA, M. I. C.; SILVA, K. S.; JÚNIOR, S. C. G.; FONSECA, V. M. Resultado do teste rápido antiHIV após o parto: uma ameaça à amamentação ao nascimento. Rev Saúde Pública. 2010; 44(1):60-9.

PARIZOTTO, J.; ZORZI, N. T. Aleitamento Materno: fatores que levam ao desmame precoce no município de Passo Fundo, RS. O Mundo da Saúde. São Paulo 2008; 32 (4):466-474. 
PASSANHA, A.; CERVATO-MANCUSO, A. M.; SILVA, M. E. M. P. Elementos protetores do leite materno na prevenção de doenças gastrintestinais e respiratórias. Rev. bras. crescimento desenvolv. hum. [online]. 2010, vol.20, n.2, pp. 351-360. ISSN 01041282.

PEREIRA, E. C.; FERNANDES, R. A. Q.; SABATES, A. L. Prevalência de aleitamento materno exclusivo em crianças de uma comunidade carente do município de São Paulo. Revista enfermagem atual in derme. 2012; 63 35-39.

RAMOS, C. V.; ALMEIDA, J. A. G.; ALBERTO, N. S. M. C.; TELES, J. B. M.; SALDIVA, S. R. D. M. Diagnóstico da situação do aleitamento materno no Estado do Piauí, Brasil. Cad. Saúde Pública, Rio de Janeiro, 24 (8):1753-1762, ago, 2008.

SCHMITZ, E. M. R. A enfermagem em pediatria e puericultura. São Paulo: Editora Atheneu, 2005.

VIEIRA, R. W. et al. Do aleitamento materno à alimentação complementar: atuação do profissional nutricionista. Saúde \& Amb. Rev., Duque de Caxias, v.4, n.2, p.1-8, juldez. 2009. 